\title{
A ação do fogo sobre os componentes do concreto
}

\section{The action of the fire on the components of the concrete}

\author{
Gilson Morales $^{1}$; Alessandro Campos ${ }^{2}$; Adriana M. Patriota Faganello ${ }^{3}$
}

\section{Resumo}

O concreto é um material composto, onde diferentes materiais que o constituem não reagem da mesma forma diante da ação do fogo, tornando seu efeito sobre as estruturas de concreto um problema. O tempo de exposição, nível de temperatura alcançado e o traço do concreto, influenciarão no grau de alteração que poderá ser produzido no concreto afetado por esses fatores. Para estudar os efeitos do fogo, onde cada incêndio tem suas características, é necessário realizar um fogo real, devido às variáveis. Podemse analisar os efeitos produzidos pelo fogo no concreto armado observando os resultados obtidos na argamassa, no aço, na vinculação entre ambos, as conseqüências das dilatações quando impedidas total ou parcialmente e produção de esforços resultantes dos incêndios. Foram analisados os efeitos da elevação da temperatura em corpos de prova cilíndricos de argamassa, mantidos em câmara úmida, ao ar, durante 7 dias. Foi utilizado areia média silicosa de rio e cimento Portland $\mathrm{CP}-\mathrm{V}$, submetidos à elevação de temperatura em mufla. Os concretos submetidos à ação do fogo perdem consideravelmente sua resistência, onde, conforme o aumento de temperatura, aumenta sua perda, e sua a elasticidade fica abaixo dos níveis desejados, conforme pode se confirmar estes dados através da revisão bibliográfica.

Palavras-chave: Ação do fogo em concretos. Efeito da temperatura em argamassas. Efeito de incêndios em edifícios

\begin{abstract}
The concrete is a composed material where different materials constitute that it do not react ahead in the same way of the action of high temperatures, becoming the effect of the fire on the concrete structures a problem clearly. The time of exposition to the fire, reached level of temperature and the trace of the concrete, will influence in the alteration degree that could be produced in the concrete affected for these factors. To study the effect of the fire, where a fire is different of the other, it is necessary to carry through a fire real, due to the different variable. The effect produced for the fire in the armed concrete can be analyzed observing the results gotten in the mortar, the steel, the entailing enter both in the armed concrete, the consequences of the when hindered dilatations total or partially and production of resultant efforts of fires. The effect of the rise of the temperature in cylindrical bodies of mortar test had been analyzed, kept in humid chamber, to air, during 7 days. It was used siliceous sand of river and Portland cement $\mathrm{CP}-\mathrm{V}$, submitted to the rise of temperature in muffle. The concrete ones submitted to the action of the fire lose considerably its resistance, where, as the temperature increase increases its loss, and its elasticity is below of the desired levels, as it can confirm these data gotten through the bibliographical revision.
\end{abstract}

Key-Words: Action of fire in concrete. Action of temperature in mortars. Effect of fires in buildings.

\footnotetext{
1 Professor Doutor Associado do Programa de Pós-graduação em Engenharia de Edificações e Saneamento - Departamento de Construção Civil - Universidade Estadual de Londrina - UEL; gmorales@uel.br

2 Professor Mestre do Departamento de Design da UNOPAR; alessandroarq@hotmail.com

3 Professora Mestre do Departamento Arquitetura e Urbanismo da UNIFIL; adriana.faganello@unifil.br
} 


\section{Introdução}

O concreto é um material composto, cujos diferentes constituintes não reagem da mesma forma diante das altas temperaturas, o que torna o efeito do fogo um grave problema.

Segundo Figueiredo, Costa e Silva (2002), aumento da temperatura dos elementos estruturais, decorrentes da ação térmica devido aos incêndios, causa alterações na micro e na macro-estrutura do concreto.

A elevação gradual de temperatura provoca efeitos distintos no concreto e nas argamassas, verificando-se alteração na coloração, perda de resistência mecânica, esfarelamento superficial, fissuração até a própria desintegração da estrutura.

Dentre as causas que podem levar uma estrutura sujeita a altas temperaturas ao colapso, estão a temperatura máxima atingida, o tempo de exposição, o traço de concreto, o tipo de estrutura, o elemento estrutural e a velocidade de resfriamento.

O tempo de exposição e a velocidade de resfriamento estão diretamente associados ao ciclo típico de um incêndio.

Segundo Rosso (1975), o ciclo típico de um incêndio em uma edificação se constitui em três fases: a inicial, a intermediária e a final.

$\mathrm{Na}$ fase inicial verifica-se o aumento gradual da temperatura normalmente em um curto espaço de tempo, sendo que abaixo de $250^{\circ} \mathrm{C}$ o efeito da elevação da temperatura sobre a resistência mecânica do concreto é pequena. Nesta fase os valores atingidos passam a casa de $300^{\circ} \mathrm{C}$, temperatura acima da qual se acentua a queda da resistência do concreto. Nesta faixa de temperatura já ocorre uma perda considerada de resistência mecânica do concreto, fato que se acentua em situações de resfriamento rápido.

$\mathrm{Na}$ transição da fase inicial para intermediária também chamada de combustão viva, ocorre uma elevação violenta da temperatura com a propagação descontrolada das chamas chegando a ponto de irreversibilidade do incêndio. É o ponto de inflamação generalizada conhecida como flash over. Conforme Rosso (1975), nesta fase o incêndio raramente excede valores de temperatura de 1250 $1300^{\circ} \mathrm{C}$.

$\mathrm{Na}$ fase intermediária é que ocorrem os efeitos mais danosos ao concreto, os quais se agravam em função da duração da mesma. Particularmente a perda de resistência mecânica ocorre a temperaturas acima de $300^{\circ} \mathrm{C}$.

A última fase é caracterizada pela redução até a extinção do fogo, e sua influência nas estruturas de concreto se deve a forma como é feita esta extinção e a duração da mesma. O resfriamento brusco da temperatura é responsável pelas maiores perdas de resistências. Quando é realizado o resfriamento lento existe a possibilidade de recuperação de até 90\% da resistência inicial, dependendo da temperatura máxima atingida.

Segundo Neville (1923), o concreto tem boas características com respeito a resistência ao fogo, ou seja, o tempo que fica exposto ao fogo com desempenho satisfatório é relativamente grande, não ocorrendo desprendimento de gases tóxicos. Entende-se como desempenho satisfatório a capacidade de suportar cargas, a resistência a penetração de chamas e a resistência a transferência de calor.

É bem verdade que toda a perda de umidade do concreto pode resultar em queda da resistência e do módulo de deformação. Desta forma, é importante conhecer o comportamento do concreto sujeito à ação do fogo, pois dele dependerá a estabilidade estrutural da estrutura durante um período de tempo estabelecido.

Para realizar estudos dos efeitos do fogo, onde um incêndio é diferente do outro, é necessário simular uma situação real, considerando as diferentes variáveis intervenientes num sinistro. 


\section{Propriedades Térmicas do Concreto}

A condutividade térmica do concreto é baixa, variando de 1,4 e $3,6 \mathrm{~J} / \mathrm{m}^{2} \mathrm{~s}^{\circ} \mathrm{C}$ o que equivale dizer que o concreto é um mal condutor de calor.

A massa específica não interfere consideravelmente na condutividade dos concretos convencionais, porém a natureza mineralógica dos agregados exerce grande influência nesta propriedade.

Segundo Neville (1923), o basalto tem condutividade baixa, o calcário e a dolomita têm valores intermediários e o quartzo apresenta alta condutividade, sendo que neste último depende da direção do fluxo de calor em relação a orientação dos cristais pois a cristalinidade do mineral aumenta a condutividade.

O aumento do teor de umidade do concreto pode aumentar a sua condutividade, sendo que, à temperaturas elevadas, ocorre uma redução da mesma. Como a condutividade do ar é menor do que a da água, segundo Neville (1923), o aumento de $10 \%$ no teor de umidade de um concreto leve provoca um aumento de $50 \%$ em sua condutividade.

Quanto à difusibilidade térmica, ou seja, a velocidade com que ocorrem variações de temperatura na massa de concreto, os valores se situam entre 0,002 e $0,006 \mathrm{~m}^{2} / \mathrm{h}$ variando em função do tipo de agregado. Sua determinação expressa a relação entre o tempo e o diferencial de temperatura entre o interior e a superfície do concreto.

Outra variável relacionada à variação de temperatura é o calor específico, ou seja, a capacidade térmica do concreto, que varia de cerca de 800 a $1200 \mathrm{~J} / \mathrm{kg}^{\circ} \mathrm{C}$, este valor aumenta em relação a temperatura e é inversamente proporcional a massa específica do concreto.

O coeficiente de dilatação térmica do concreto é positivo dependendo da quantidade e natureza dos agregados e do teor de umidade do concreto. Vale lembrar que os coeficientes de dilatação da pasta e dos agregados são diferentes.
Segundo Figueiredo, Costa e Silva (2002), o coeficiente de dilatação térmica varia com os diferentes tipos de concretos e com a temperatura.

Conforme Neville (1923), a resistência do concreto às variações de temperaturas é inversamente proporcional ao seu coeficiente de dilatação térmica.

Segundo Anderberg (1997), as tensões térmicas de tração aparecem quando as tensões térmicas de compressão são desenvolvidas na microestrutura da face aquecida da peça de concreto e se propagam pela macroestrutura, confluindo para os cantos vivos da peça.

Devido à proximidade entre os coeficientes de dilatação térmica do aço e do concreto a utilização conjunta destes materiais resulta num excelente desempenho, porém seus coeficientes de transmissão de calor diferem bastante, sendo o aço um bom condutor de calor, enquanto o concreto um isolante térmico.

Desta forma, a análise de capacidade residual da estrutura após o incêndio é muito importante do que diz respeito à aderência entre ambos.

\section{Efeito da temperatura na composição química do concreto}

Ocorrem várias conseqüências em função da elevação da temperatura sobre os componentes do concreto. Dentre elas estão, o esfarelamento da superfície calcinada, separação parcial de pequenas camadas superficiais do material ao longo do incêndio, delaminação ou descamação profunda e lascamentos explosivos.

Delaminação, ou descamação profunda, é o destacamento de placas de concreto ao longo de grandes extensões da superfície. Este fenômeno é conhecido como "sloughing".

Lascamento explosivo, conhecido como "explosive spalling", é destacamento de pequenas placas de forma abrupta e violenta que costumam 
ocorrer nos primeiros 30 minutos da ação do fogo, a temperaturas entre $250^{\circ} \mathrm{C}$ e $400^{\circ} \mathrm{C}$.

Segundo o Neville (1923) ao se analisar apenas o comportamento do concreto exposto ao fogo, verifica-se a ocorrência de gradientes de temperatura elevados, os quais são responsáveis pela separação das camadas superficiais aquecidas na forma de lascamento.

Os lascamentos também podem ser decorrentes da evaporação da água presentes nos poros não permeáveis a qual geram uma elevação considerável da pressão interna. Segundo Purkiss (1996), estas tensões de origem térmica dentro da matriz de concreto, influem na desintegração das regiões superficiais dos elementos estruturais.

Algumas pesquisas revelam que a probabilidade de lascamentos durante um incêndio aumenta com a esbeltez de elementos estruturais e a ocorrência de altas tensões de compressão na seção ao longo de um incêndio. (COSTA; SILVA, 2002)

Quando as taxas de aquecimento são maiores, os concretos são induzidos a gradientes térmicos maiores devido a baixa condutividade do mesmo. A elevação de temperatura da superfície do elemento estrutural conduz a grandes diferenças de temperaturas entre a superfície aquecida e o interior frio do concreto (gradientes térmicos elevados) em menor tempo.

Quando o concreto é aquecido lentamente não são desenvolvidos grandes gradientes térmicos e, portanto, não há degradação imediata do material como fissuração e descamação. Mas a ausência de fissuras pode impedir a liberação da água do interior da massa de concreto, havendo possibilidade de ocorrer lascamento explosivo.

Outras formas de deterioração são a ocorrência de esfarelamento superficial decorrente da ação da alta temperatura sobre a parte carbonatada do concreto e a fissuração proveniente da evaporação de água interna ao concreto e da dilatação térmica dos componentes e posteriores resfriamentos.
Ferreira (1998) destaca ainda a ocorrência de outros danos causados ao concreto submetido à ação do fogo: calcinação superficial, movimentos de dilatação e retração estrutural e movimentação da armadura devido a dilatação do aço.

A ocorrência de fissuras costuma-se ocorrer nas juntas, nos pontos de adensamento deficiente ou nos planos das barras da armadura. É importante destacar que as barras expostas ao calor podem servir de condutores e acelerarem o processo de degradação.

A elevação da temperatura também interfere na coloração do concreto, variando de tons rosáceos nas temperaturas mais baixas, passando por tons cinza em temperaturas intermediárias e chegando a tons esbranquiçados e amarelecidos a altas temperaturas.

\section{Efeito da temperatura nas propriedades fisicas} do concreto

São vários os efeitos decorrentes da elevação de temperatura sobre o concreto. Rosso (1975) apresenta o seguinte esquema deste comportamento:

100-500 ${ }^{\circ} \mathrm{C}$ - Lascamento, "explosive spalling", início do processo de desidratação do gel de C-S-H, que se intensifica em $300^{\circ} \mathrm{C}$ e prossegue até próximo de $400^{\circ} \mathrm{C}$;

$200^{\circ} \mathrm{C}$ - idem e retração por perda de água da tobermorita e dilatação dos agregados;

$300-400^{\circ} \mathrm{C}$ - Redução da águan do gel com a formação de silicatos anidros ocorrendo fissuras superficiais;

$400-\mathbf{5 0 0}^{\circ} \mathbf{C}$ - Idem e retração acentuada por desidratação do hidróxido de cálcio;

$500-600^{\circ} \mathrm{C}$ - Desidratação mais rápida do hidróxido de cálcio;

$\mathbf{5 7 5}^{\circ} \mathrm{C}$ - Expansão do quartzo na transformação de alfa para beta, com fissuração da matriz cimentícia;

$600^{\circ} \mathrm{C}$ e $7_{00}^{\circ} \mathrm{C}$ - Transformações de outros 
agregados; $\mathrm{O} \mathrm{CaCO} 3$ começa a se transformar em Cão e a liberar $\mathrm{CO} 2$.

$\mathbf{8 0 0}^{\circ} \mathrm{C}$ - Retração por perda de água combinada da tobermorita;

$\mathbf{8 7 0}^{\circ} \mathrm{C}$ - Expansão do quartzo na transformação de beta em tridimita.

Segundo Rosso (1975), a partir da temperatura básica teórica de $300^{\circ} \mathrm{C}$, começam a ocorrer prejuízos consideráveis na resistência mecânica de um componente de concreto.
A partir de aproximadamente $500^{\circ} \mathrm{C}$, as dilatações ocorridas no concreto de agregados silicosos e no aço são muito semelhantes, sendo que, a partir de $300^{\circ} \mathrm{C}$ a cor do concreto começa a sofrer alteração de tonalidade. Até atingir a casa dos $600^{\circ} \mathrm{C}$ a tonalidade varia de tons róseos a vermelho pálido, devido à alteração dos compostos de ferro. Acima de $600^{\circ} \mathrm{C}$ a tonalidade varia de cinza claro a amarelo claro. Além da alteração da tonalidade, a observação visual das superfícies sujeitas a sinistros pode revelar informações importantes, conforme a Tabela 01.

Tabela 1. Características do concreto superaquecido

\begin{tabular}{|c|c|c|}
\hline Temperatura $\left[{ }^{\circ} \mathrm{C}\right]$ & Cor & Aspecto visual / Desempenho \\
\hline$<250$ & Cinza & Perda de resisência pequena e irregular \\
\hline $285-300$ & Cinza-Roseo & $\begin{array}{l}\text { Fissuração superficial, lascamento } \\
\text { explosivo (vapor) }\end{array}$ \\
\hline 300 & Rosa & Início de mudança de cor \\
\hline $50-400$ & & Redução do módulo de deformação \\
\hline $535-550$ & Roxo & $\begin{array}{l}\text { Fissuração profunda - } \\
\text { friabilidade superficial }\end{array}$ \\
\hline 575 & Vermelho pálido & $\begin{array}{l}\text { Pipocamento dos } \\
\text { grâos de quartzo }\end{array}$ \\
\hline 650 & Cinza esbranquiçado & Perda das propriedades mecânicas \\
\hline $790-800$ & & $\begin{array}{l}\text { Lascamentos do cobrimento das } \\
\text { armaduras, com exposição até } 25 \% \text { da } \\
\text { superfície das mesmas }\end{array}$ \\
\hline 900 & Amarelo alaranjado & Superfície pulverulenta \\
\hline 1000 & Amarelo claro & \\
\hline
\end{tabular}

Fonte: Rosso (1975) apud Neville (1923)

Efeito da temperatura nas propriedades mecânicas do concreto

O teor de umidade do concreto é um fator preponderante na perda de resistência, a qual é mais acentuada nos concretos saturados. O problema é originado devido ao aumento da pressão do vapor de água que se verifica no interior da massa, a qual pode superar a resistência do concreto a tração e provocar a presença de trincas e explosões, considerando ainda que a resistência a flexão seja mais alterada pela elevação de temperatura do que a resistência à compressão.

Segundo Lima et al (2004), a aderência entre a pasta de cimento e o agregado graúdo é altamente prejudicada pela elevação de temperatura.

Nos concretos de maior idade, nos quais já 
ocorreram a colmatação dos vazios microscópicos, aumentando a sua impermeabilidade, se acentuam o risco da ocorrência de explosões. Desta forma, concretos mais pobres são menos susceptíveis a este fenômeno bem como sofrem menor redução da resistência do que concretos ricos.

Segundo Neville (1923), a perda de resistência do concreto é menor quando o agregado não contém sílica, caso das rochas calcárias, rochas ígneas básicas, material cerâmico e escória de alto forno.

As perdas de resistências abaixo da temperatura de $300^{\circ} \mathrm{C}$ não são consideráveis, porém acima deste valor os resultados comprometem a integridade estrutural.

Para situações em que a temperatura não ultrapasse os $500^{\circ} \mathrm{C}$, através de reidratação posterior o concreto poderá recuperar até $90 \%$ da resistência mecânica original no prazo de um ano.

Segundo Neville (1923) entre $600^{\circ} \mathrm{C}$ e $700^{\circ} \mathrm{C}$ ocorre a perda total e irreversível das propriedades mecânicas do concreto. A Tabela 02 e o Gráfico 01 mostram as perdas de resistência nas respectivas temperaturas.

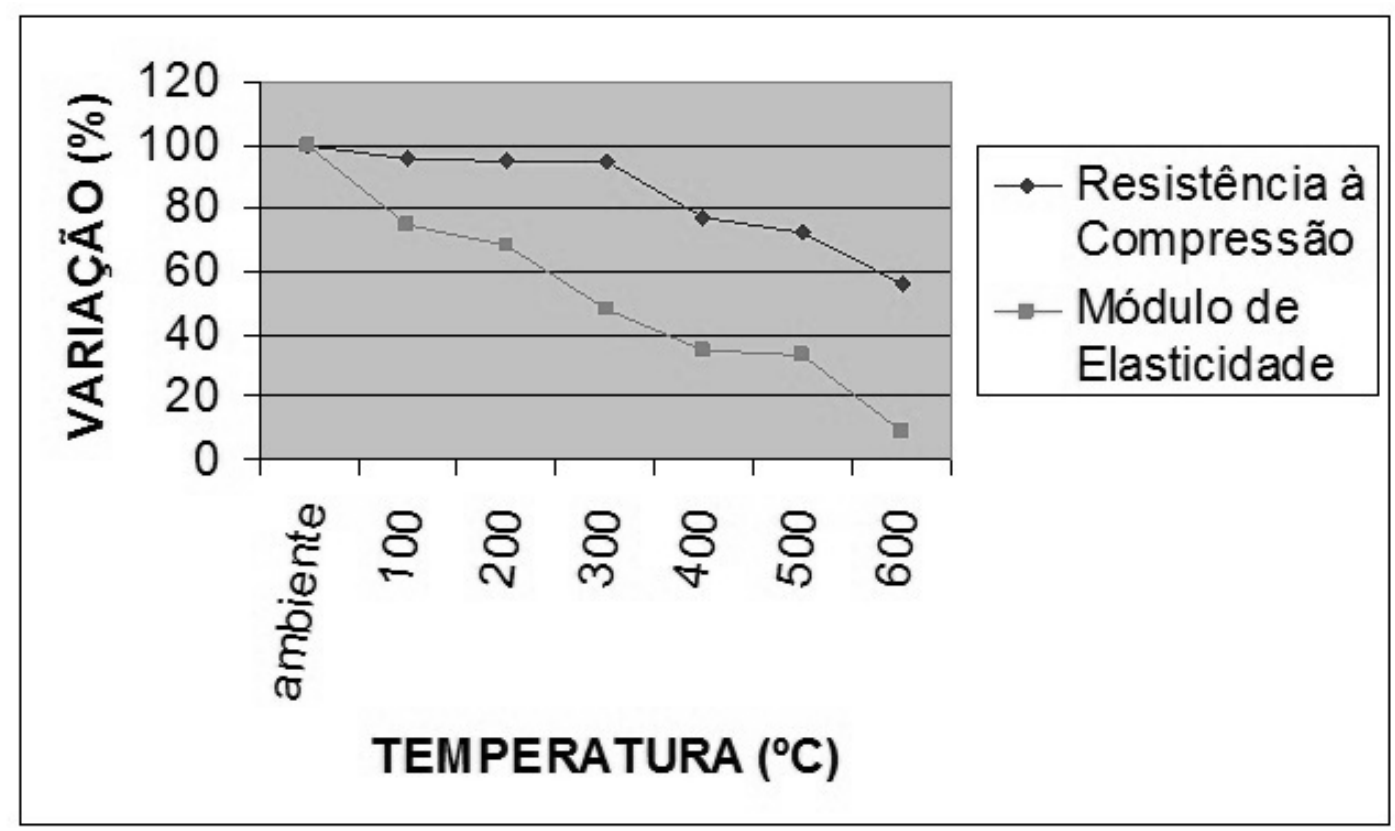

Gráfico 1. Variação da Resistência à Compressão e do Módulo de Elasticidade em função da elevação temperatura. Fonte: Neville (1923)

\section{Materiais e Métodos}

\section{Amostras}

No presente trabalho optou-se em analisar os efeitos da elevação da temperatura em corpos de prova cilíndricos de argamassa, com as seguintes dimensões: $\varnothing 5 \times 10 \mathrm{~cm}$. Foram moldados 06 corpos de prova por lote, utilizando a mesma composição da argamassa de um traço de concreto.
Traço

O traço em massa utilizado foi 1:3 e a relação água/cimento 0,44 . Os corpos de prova foram mantidos em câmara úmida, ao ar, durante 7 dias.

Os materiais utilizados foram: areia media silicosa de rio e cimento Portland CP-V. 


\section{Aquecimento e resfriamento}

Após 7 dias os corpos de prova foram submetidos a elevação de temperatura em mufla, com taxa de aquecimento de $20^{\circ} \mathrm{C} / \mathrm{min}$ até os patamares especificados.

Os lotes de corpos de prova eram mantidos nos patamares de temperatura durante 4 horas. Após este intervalo de tempo, a mufla era aberta e retirado o lote. Em seguida o lote era submetido a resfriamento brusco, através da imersão num recipiente com água, à temperatura de $21^{\circ} \mathrm{C}$. Outros lotes eram mantidos no interior da mufla até o completo resfriamento do conjunto. Em paralelo foi moldado um lote de corpos de prova de referência, que foram mantidos na câmara úmida até a ruptura.

Os corpos de prova foram submetidos aos patamares de temperatura de $300^{\circ} \mathrm{C}, 350^{\circ} \mathrm{C}, 400^{\circ} \mathrm{C}$, $450^{\circ} \mathrm{C}$ e $750^{\circ} \mathrm{C}$.

\section{Ruptura}

Após resfriados, os corpos de prova foram capeados com uma mistura de enxofre e pozolana, e submetidos à ruptura através de compressão axial.

\section{Resultados}

Os corpos de prova foram aquecidos aos patamares de temperatura de $300^{\circ} \mathrm{C}, 350^{\circ} \mathrm{C}, 400^{\circ} \mathrm{C}, 450^{\circ} \mathrm{C}$ e $750^{\circ} \mathrm{C}$, com taxa de aquecimento de $20^{\circ} \mathrm{C} / \mathrm{min}$. Inicialmente, após aquecidos, os corpos de prova foram submetidos a resfriamento rápido e lento. Observou-se uma redução de 5,2\% na resistência à compressão dos corpos de prova aquecidos a $300^{\circ} \mathrm{C}$ e submetidos a resfriamento lento. Por outro lado, os corpos de prova submetidos a resfriamento brusco, apresentaram uma perda de 30,5\% na resistência à compressão.

Posteriormente, os corpos de prova aquecidos aos patamares de temperatura de $300^{\circ} \mathrm{C}, 350^{\circ} \mathrm{C}$, $400^{\circ} \mathrm{C}, 450^{\circ} \mathrm{C}$ e $750^{\circ} \mathrm{C}$, foram submetidos apenas a resfriamento lento seguido da ruptura à compressão. Os corpos de prova aquecidos a $750^{\circ} \mathrm{C}$ apresentaram esfarelamento e desagregação, não sendo possível realizar sua ruptura à compressão, sendo que os mesmos apresentaram tonalidade rosácea, conforme a Figura 1.

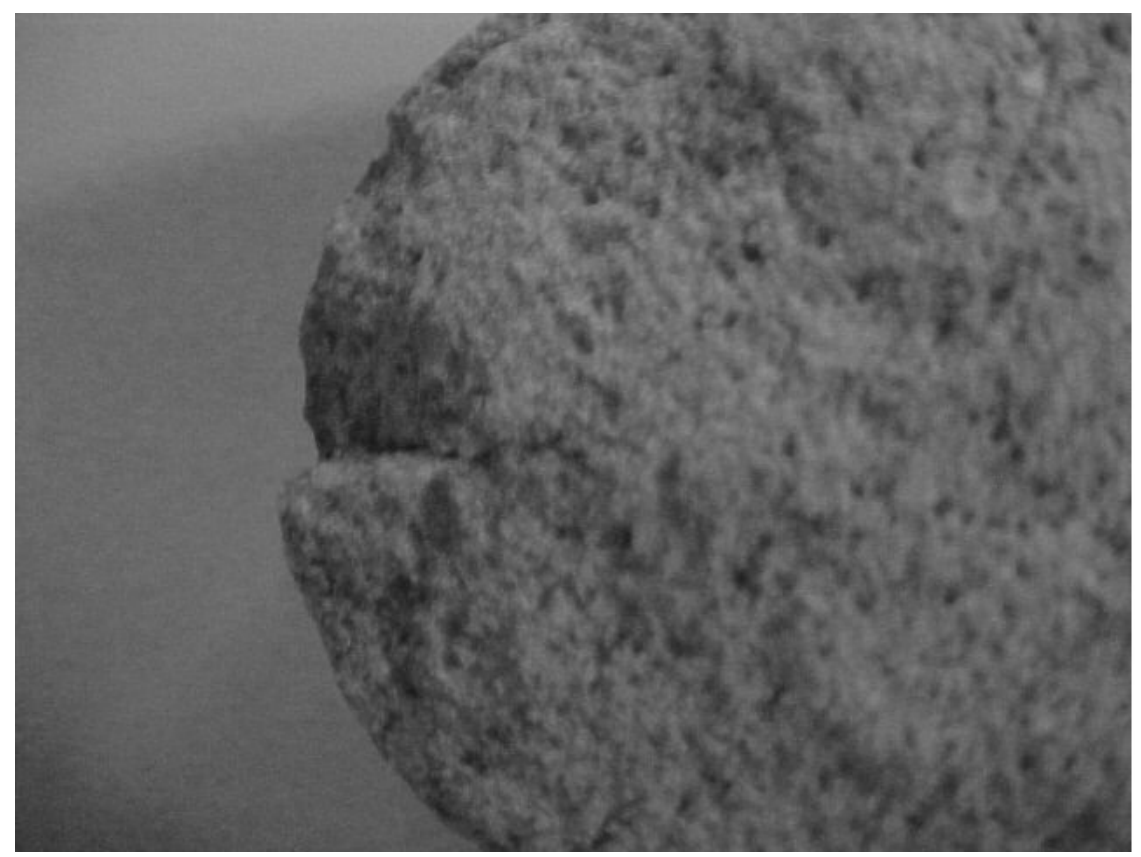

Figura 1. Corpo de prova de argamassa após aquecimento a $750^{\circ} \mathrm{C}$. 
Após o resfriamento, os corpos de prova resultados constantes da Tabela 3. foram submetidos à compressão, apresentando os

Tabela 3. Valores da Resistência Média à Compressão dos corpos de prova submetidos a $300^{\circ} \mathrm{C}, 350^{\circ} \mathrm{C}, 400^{\circ} \mathrm{C}$ e $450^{\circ} \mathrm{C}$.

\begin{tabular}{c|r|c|c|c}
\hline $\begin{array}{c}T \\
\left({ }^{\circ} \mathrm{C}\right)\end{array}$ & fcj7 & \multicolumn{1}{|c|}{ perda } & $\mathbf{E}$ & perda \\
\hline REF & 18,70 & 0 & 34,40 & 0 \\
\hline $\mathbf{3 0 0}$ & 13,50 & 28 & 18,60 & 46 \\
\hline $\mathbf{3 5 0}$ & 13,00 & 30 & 17,10 & 50 \\
\hline $\mathbf{4 0 0}$ & 9,50 & 49 & 14,50 & 58 \\
\hline $\mathbf{4 5 0}$ & 6,80 & 64 & 9,40 & 73 \\
\hline
\end{tabular}

\section{Conclusões}

Os concretos submetidos à temperaturas elevadas, superiores a $300^{\circ} \mathrm{C}$, perdem consideravelmente sua resistência mecânica à compressão, porém até $300^{\circ} \mathrm{C}$, a perda de resistência é mínima, em torno de $5 \%$, aumentando conforme se eleva a temperatura. Os corpos de prova de argamassas de cimento e areia submetidos a $300^{\circ} \mathrm{C}$ com resfriamento lento, perderam em torno de $5 \%$ de sua resistência, enquanto que, com o resfriamento rápido, perderam entre 28 a $30 \%$ de sua resistência. As amostras submetidas a $750^{\circ} \mathrm{C}$ perderam totalmente a resistência mecânica.

A redução do módulo de elasticidade nas amostras submetidas a $300^{\circ} \mathrm{C}$, com resfriamento lento, foi da ordem de $46 \%$, enquanto que nas submetidas a $450^{\circ} \mathrm{C}$, foi de cerca de $73 \%$.

O efeito da elevação da temperatura sobre o concreto e as argamassas de cimento é pequeno e de certa forma irregular até os $250^{\circ} \mathrm{C}$. Este efeito se torna bastante acentuado e compromete a integridade da estrutura quando a temperatura ultrapassa os $300^{\circ} \mathrm{C}$, principalmente nos casos em que esta elevação é seguida do resfriamento rápido.

\section{Referências}

ANDERBERG, Yngve. Spalling phenomena of HPC and OC. In: PHAN, Long T.; CARINO, Nicholas J.; DUTHINH, Dat; GARBOCZI, Edward. INTERNATIONAL WORKSHOP ON FIRE PERFORMANCE OF HIGH-STRENGTH CONCRETE, 1997, Gaithersburg, MD. Proceedings... Gaithersburg (E.U.A.): National Institute of Standards and Technology, 1997. p. 69-73.

COSTA, C. N.; SILVA, V. P. Estruturas de concreto em situação de incêndio. In: JORNADAS SULAMERICANAS DE ENGENHARIA ESTRUTURAL, 30., 2002, Brasília. Anais... Brasilia: PECC-UnB/ ASAEE, 2002.

FERREIRA, Sérgio Gonçalves. "Ação do incêndio nas estruturas de aço - conseqüencias e recuperação”. In: Simpósio Nacional de Arquitetura e Proteção Contra Incêndios. Anais. EPUSP. São Paulo, 1998.

FIGUEIREDO, A. D.; COSTA, C. N.; SILVA, V. P. Aspectos tecnológicos dos materiais de concreto em altas temperaturas. In: SEMINÁRIO INTERNACIONAL NÚCLEO DE PESQUISA EM TECNOLOGIA DA ARQUITETURA E URBANISMO, 2002, São Paulo. Anais... São Paulo: NUTAU/FAU-USP, 2002.

LIMA, R. C. A.; KIRCHHOF L. D.; CASONATO, C. A.; SILVA FILHO, L. C. P. Efeito de altas temperaturas no concreto. In: SEMINÁRIO DE PATOLOGIAS DAS EDIFICAÇÕES, 2, 2004, Porto Alegre. Anais... Porto Alegre: UFRGS., 2004.

NEVILle, A. M. Propriedades do concreto. São Paulo: Pini, 1923. 
PURKISS, J. A. Fire safety engineering design of structures. . Oxford: Butterworth Heinemann, 1996.

ROSSO, T. Incêndios e arquitetura. Apostila. São Paulo: FAUUSP, 1975.

Recebido em 17 Dezembro, 2009 - Received on December 17, 2009.

Aceito em 27 Janeiro, 2011 - Accepted on January 27, 2011. 
